Technical Paper

Doi: http://dx.doi.org/10.1590/1809-4430-Eng.Agric.v42n1e20210200/2022

\title{
TEST OF THE SCREENING AND PARAMETER OPTIMIZATION OF SWING SEPARATION SIEVE IN FIELD OPERATION
}

\author{
Jianguo Meng1, Xiang Zhao ${ }^{1 *}$, Minglu Chi² ${ }^{*}$, Kai Wang ${ }^{1}$, Shengshi Xie ${ }^{3}$
}

\author{
$1^{1 *}$ Corresponding author. Inner Mongolia University of Science and Technology/ Baotou, China. \\ E-mail: zxloveqdp@163.com | ORCID ID: https://orcid.org/0000-0002-8697-7917 \\ $2^{*}$ Corresponding author. Henan Institute of Technology/ Xinxiang, China. \\ E-mail: ccmml186@163.com | ORCID ID: https://orcid.org/0000-0001-6183-8702
}

\section{KEYWORDS}

potato-soil mixture, dynamic tracking technology, orthogonal regression test, sieving characteristics, response surface analysis.

\begin{abstract}
The need for clarity regarding the sieving characteristics of the potato-soil mixture, as provided by the swing separating sieve of a potato digger, as well as the derived problems of low potato transportation efficiency, a high potato damage rate and low potato unearthing rate, are the main reasons for this study. Dynamic tracking technology is proposed to collect the motion state of potatoes, during the process of potato and soil separation. Considering the potato conveying speed, potato unearthing rate and potato damage rate as indicators, while the sieving parameters (crank rotational speed, sieve inclination, crank radius and swing direction angle) are the influencing factors, an orthogonal regression test is carried out, where the response surface is used to analyze each factor, its influence on the screening index, and to optimize it accordingly. The test results show that there is a linear relationship between the screening parameters and indexes, with each parameter showing different contribution rates to the screening indexes. The best parameter combination is the crank rotational speed of $190 \mathrm{r} / \mathrm{min}$, sieve inclination of $9.7^{\circ}$, crank radius of $40 \mathrm{~mm}$ and swing direction angle of $18.8^{\circ}$. The corresponding potato conveying speed, unearthing rate and damage rate is $0.713 \mathrm{~m} / \mathrm{s}, 98.7 \%$ and $3.224 \%$, respectively. After optimization, the potato conveying speed is 1.43 times higher, the unearthing rate is increased by $2.5 \%$ and the damage rate is reduced by $60 \%$. The research results can provide theoretical support to the structural design of potato diggers.
\end{abstract}

\section{INTRODUCTION}

In China, the main potato production areas mostly employ semi-mechanized harvesting methods, using small and medium-sized potato diggers. The potato-soil screening device is the core equipment of the potato digger, while its screening capacity determines the working performance of the equipment. These devices generally include a swing or vibration type element ( $\mathrm{Lv}$ et al., 2015), a poking roller (Wang et al. 2017b; Yang et al., 2016), a disc grid (Shi et al., 2012), a poke finger wheel (Wu et al., 2010, 2011), as well as an elevating chain part (Wei et al., 2018; Zhang et al., 2021). Swing-sieve potato diggers are widely used in the central and western regions of China. A swing separator is the most commonly used separation equipment for potato and tuber diggers (Meng et al. 2022). Modifying the screening parameters will change the kinematics and dynamics of the potato-soil mixture on the sieve surface, which in turn affects the screening performance of the sieve. Therefore, determining the sieving characteristics of the oscillating separating sieve plays a vital role in improving the sieving performance of the device and improving the potato-soil separation effect along with the total production efficiency of the potato digger.

Over the years, the research on the swing separating sieve has mainly focused on simulation and optimization. Meng et al. (2020) used 3D scanning to establish a three-dimensional model of irregularly shaped potatoes and used discrete element simulation analysis software to simulate the movement of the potato on the sieve surface,

\footnotetext{
${ }^{1}$ Inner Mongolia University of Science and Technology/ Baotou, China.

${ }^{3}$ Inner Mongolia Agricultural University/ Hohhot, China.
} 
while exploring the influence of the sieve inclination and swing frequency changes on the potato motion speed. Xie et al. (2019) tested the coverage rate of the potato-soil mixture as an evaluation index, analyzed the changing mechanism of the distribution height of potato-soil mixture and optimized the swing sieve function. At present, there are few reports on the comprehensive analysis of the influence of changes of various swing sieve parameters on the potato-soil motion state and sieving performance, based on experimental methods.

The purpose of this study is to reveal the sieving characteristics of potato-soil mixture sieving by a swing separation sieve, determine the induced potato mechanical damage and screening mechanism, as well as to regulate and optimize the screening parameters, thus providing a reference basis for the structural improvement and parameter regulation of potato digger sieving devices.

\section{MATERIAL AND METHODS}

\section{Overall structure and working principle of swing separation sieve}

The swing separation sieve of a $4 \mathrm{SW}-170$ potato digger mainly includes the transmission shaft, reduction gearbox, sprocket transmission mechanism, rotating shaft, crank, connecting rod, front and rear swing rods, screen angle adjustment mechanism, side plate and screen rod (Figure 1).

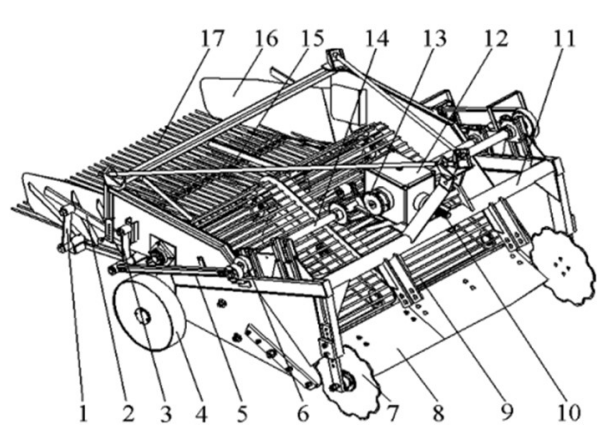

a. Overall structure of potato digger

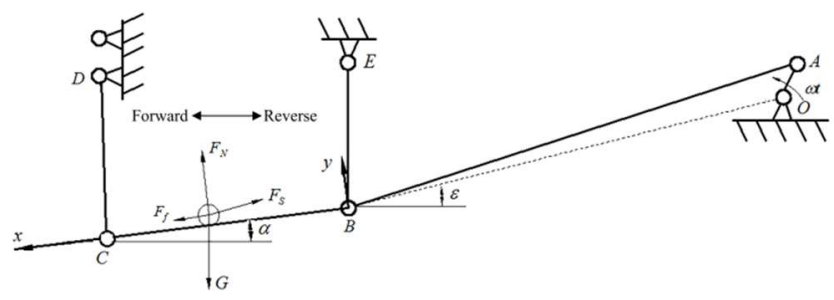

b. Diagram of swing separation sieve mechanism

1. Rear swing rod 2. Screen angle adjusting mechanism 3. Front swing rod 4. Traveling wheel 5. Connecting rod 6. Crank 7. Soil cutting disc 8. Digging shovel 9. Lifting chain 10. Transmission shaft 11. Frame 12. Reduction gearbox 13. Sprocket drive mechanism14. Rotating shaft 15. Upper screen 16. Side plate 17. Lower screen

FIGURE 1. Overall structure of potato digger and diagram of swing separation sieve mechanism.

The sieve surface $\mathrm{BC}$ is articulated to the frame through the front and rear swing rods $\mathrm{BE}$ and $\mathrm{CD}$. The crank $\mathrm{OA}$ drives the connecting rod $\mathrm{AB}$ to push the sieve surface $\mathrm{BC}$ to reciprocate with the crank radius $r$ and the swing direction angle $\delta(\delta=\varepsilon-\alpha, \alpha$ is the sieve inclination). For the convenience of analysis, it is approximately considered that the swing separation sieve is swinging in a straight line.

During the operation of the unit, the mixture, mainly composed of potatoes and soil along with a small amount of weeds, is excavated and transported to the swing separation sieve, by a lifting chain. The swing sieve moves back and forth, driven by the crank and connecting rod mechanism, while the soil falls to the ground through the screen rod gap as the potatoes are transported to the screen tail and laid on the ground (Xie et al., 2017).

\section{Conditions and equipment}

In October 2020, an experiment was conducted in a potato experimental base in Hohhot, Inner Mongolia, where the field was dry land ridge sown, flat terrain and the soil type was sandy loam. The average soil moisture content was $10.42 \%$ and the average hardness value was $246.1 \mathrm{~N} / \mathrm{cm}^{2}$; potato variety: Kexin 1, planting depth: 26 31 cm, digging depth: $35 \mathrm{~cm}$, test temperature: $21.4^{\circ} \mathrm{C}$. Before the test, the sundries (seedling grass) were removed from the test site.

The test machine is a $4 \mathrm{SW}-170$ potato digger, with supporting power from a John Deere 904 tractor (90 HP).
The equipment includes a high-speed camera, photoelectric tachometer, tape measure and a stopwatch. The camera is a Phantom Miro 2 high-speed digital camera, produced by Vision Research, with a resolution of $640 \times$ 480 pixels and frame rate of 200 frames / s.

\section{Ranges of test-factor values}

The sieving characteristics of potato-soil mixture by a swing separation sieve are mainly related to the crank rotational speed, sieve inclination, crank radius and swing direction angle. Prior to the test, the test factors were selected according to the structure of the screen body, considering the following points: (1) Based on production experience, when the potato digger works normally in the field, the crank rotational speed should range from 160 to $210 \mathrm{r} / \mathrm{min}$. (2) The pretest shows that, at the sieve inclination angle of $0.5^{\circ}$, in the same swing cycle, the forward and backward displacement motion of the potato on the sieve surface appears to be wide, while the potato skin is seriously damaged and the transportation efficiency is low; when the inclination angle of the swing sieve is $14^{\circ}$, the tail of the sieve body is in contact with the field soil, resulting in the failure of the normal swing separation sieve operation. Therefore, the range of sieve inclination of $4.7 \sim 9.7^{\circ}$ was set. (3) Due to the structural design, the minimum crank radius is $35 \mathrm{~mm}$. When the crank radius is greater than $45 \mathrm{~mm}$, the bearing seat screws of the crank shaft are easily loosened and the stability of the machine structure appears reduced, even under normal working 
conditions. Therefore, the crank radius selection handle is set to $35 \sim 45 \mathrm{~mm}$. (4) The swing direction angle affects the vibration direction of the material, the linear and nonlinear force and falling impact force of the material in the $\mathrm{X}$ and $\mathrm{Y}$ directions of the sieve surface. Theoretical analysis shows that the selection range of the swing direction angle should not be too large, and the range of $16.8 \sim 18.8^{\circ}$ (Xin et al., 2009) is acceptable.

\section{Test process}

The test shall be conducted according to the test method, as specified in the agricultural industry standard of the People's Republic of China "NY / T 648-2015 technical specifications of quality evaluation for potato harvesters". The stable distance for a single test shall be 30 $\mathrm{m}$, with a $20 \mathrm{~m}$ preparation area and end area to be set respectively.

Before the test, the absolute coordinates and relative coordinates on the swing separation sieve are set, in which the absolute coordinates are set at the frame (not the swing with the sieve body), and the relative coordinates are set at the baffle of the separation sieve. Aiming at the problem of distance compensation, that is, recording the horizontal displacement of the camera installation position from the absolute coordinates and relative coordinates, combined with the camera's ability to capture the complete movement of the potato on the sieve surface, the horizontal displacement of the camera from the origin of the absolute coordinates should be $2.2 \mathrm{~m}$ when the fixed bracket is installed. Its horizontal displacement from the origin of the relative coordinate is $2.55 \mathrm{~m}$, as shown in Figure 2a.

Acquisition method: a high-speed camera is welded on the frame of the potato digger with a support, an acquisition ruler is set on the side plate of the swing sieve, the baffle on the other side is removed, the angle is adjusted and the dynamic change process of the potatosoil mixture and potato is photo recorded. During the test, first, the high-speed camera is set in the recording mode and the tractor starts. After the tractor and potato digger are established in a stable operation phase, the high-speed camera starts to collect real-time data. During the test, different values of the test factors are selected, and the test is run 5 times. The average values are considered as the test results. The test system and acquisition process are shown in Figure 2.

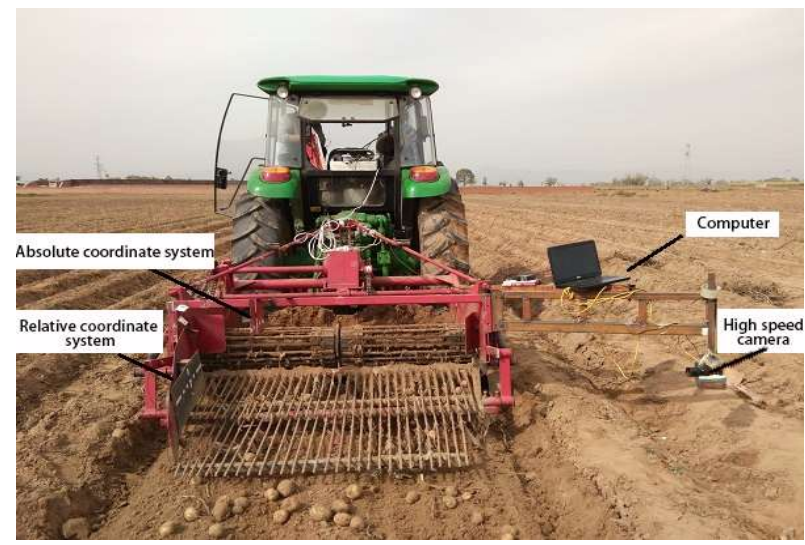

a. Test system

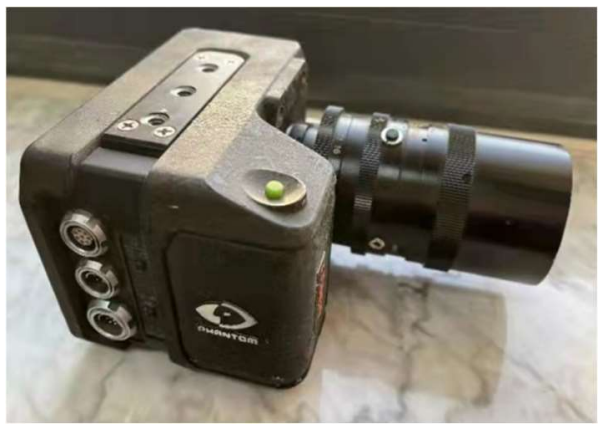

b. High-speed digital camera

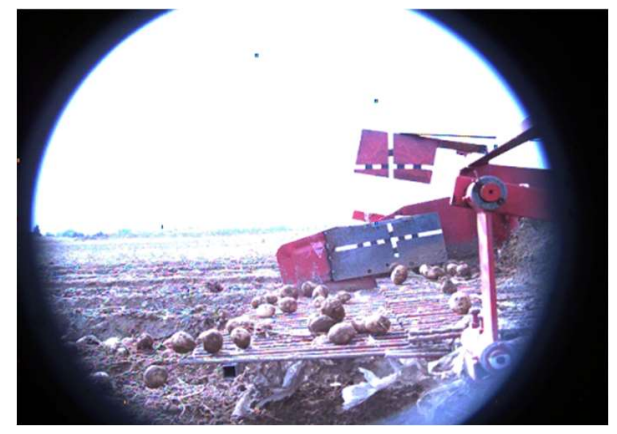

c. Collection process

FIGURE 2. Test system and collection process.

\section{Orthogonal polynomial regression test}

The sieving characteristics of a potato-soil mixture by the swing separation sieve method mainly concern the potato-soil separation effect, potato motion state, transportation efficiency and velocity change. Specifically, the effect of potato-soil separation mostly refers to the rate of damaged potatoes derived and the rate of potato unearthing. The potato motion state is about sliding, rolling, jumping and other composite motion states, whereas the conveying efficiency refers to the conveying speed of potatoes in relation to the sieve surface. Therefore, considering the crank rotational speed, sieve inclination, crank radius and swing direction angle as factors, while the potato conveying speed (average speed), potato unearthing rate and damaged potato rate are used as screening indexes, the sieving performance of the swing separation sieve is analyzed by orthogonal regression. 


\section{Test setup and method}

According to "NY/T 648-2015 technical specifications of quality evaluation for potato harvesters" in China, the potato conveying speed is $v$, the potato unearthing rate is $Q$ and the damaged potato rate is $Z$. The calculation formulas are as follows:

$$
\begin{aligned}
& v=\frac{S}{t} \\
& Q=m_{1} / M \times 100 \% \\
& Z=m_{2} / M \times 100 \%
\end{aligned}
$$

Where:

$S$ is the length of the sieve surface $(\mathrm{mm})$;

$t$ is the potato motion time on it (s);

$m_{1}$ is the mass of potatoes exposed on the soil surface after screening $(\mathrm{kg})$;

$m_{2}$ is the mass of damaged potatoes after screening $(\mathrm{kg})$,

$M$ is the total mass of potatoes after screening $(\mathrm{kg})$.

According to the Box-Behnken central composite design theory, the significance test and response surface analysis of four main parameters affecting the potato conveying speed, potato unearthing rate and damage rate are carried out (Wang et al., 2017a; Fu et al., 2018; Cui et

\begin{tabular}{|c|c|c|c|c|}
\hline Levels & $\begin{array}{c}\text { Crank rotational speed } \\
\text { A }(r / \mathrm{min})\end{array}$ & $\begin{array}{c}\text { Sieve inclination } \\
\mathrm{B}\left({ }^{\circ}\right)\end{array}$ & $\begin{array}{c}\text { Crank radius } \\
\mathrm{C}(\mathrm{mm})\end{array}$ & $\begin{array}{l}\text { Swing direction angle } \\
\mathrm{D}\left(\left(^{\circ}\right)\right.\end{array}$ \\
\hline-1 & 160 & 4.7 & 35 & 16.8 \\
\hline 0 & 185 & 7.2 & 40 & 17.8 \\
\hline 1 & 210 & 9.7 & 45 & 18.8 \\
\hline
\end{tabular}
al., 2021).

TABLE 1. Sieving parameter values.

The factor values are listed in Table 1, while the test design scheme and data statistics of the response values are shown in Table 2. 
TABLE 2. Test plan and response value data statistics.

\begin{tabular}{|c|c|c|c|c|c|c|c|}
\hline \multirow{2}{*}{ No. } & \multicolumn{4}{|c|}{ Sieving parameters } & \multirow{2}{*}{ Potato conveying speed (m/s) } & \multirow{2}{*}{ Potato unearthing rate $(\%)$} & \multirow{2}{*}{ Potato damage rate $(\%)$} \\
\hline & A & B & $\mathrm{C}$ & $\mathrm{D}$ & & & \\
\hline 1 & 0 & 0 & 0 & 0 & 0.51 & 97.2 & 5.3 \\
\hline 2 & -1 & 0 & 1 & 0 & 0.39 & 96.1 & 8.5 \\
\hline 3 & 0 & 1 & 0 & 1 & 0.49 & 97.3 & 0.9 \\
\hline 4 & 0 & 1 & 0 & -1 & 0.63 & 95.7 & 1.1 \\
\hline 5 & 1 & 0 & 0 & -1 & 0.66 & 97.4 & 5.8 \\
\hline 6 & 1 & 0 & 1 & 0 & 0.83 & 100 & 9.7 \\
\hline 7 & -1 & 1 & 0 & 0 & 0.36 & 94.7 & 4.3 \\
\hline 8 & -1 & 0 & 0 & -1 & 0.39 & 95.1 & 4.5 \\
\hline 9 & 0 & 0 & -1 & -1 & 0.39 & 95.1 & 0.3 \\
\hline 10 & 0 & 0 & 0 & 0 & 0.49 & 97.1 & 4.9 \\
\hline 11 & 1 & 0 & 0 & 1 & 0.53 & 98.3 & 7.2 \\
\hline 12 & 0 & -1 & -1 & 0 & 0.18 & 96.5 & 3.2 \\
\hline 13 & 0 & 0 & -1 & 1 & 0.31 & 96.5 & 2.4 \\
\hline 14 & 0 & 0 & 0 & 0 & 0.53 & 96.3 & 4.6 \\
\hline 15 & 0 & -1 & 0 & -1 & 0.38 & 97.4 & 3.2 \\
\hline 16 & 0 & 0 & 1 & 1 & 0.57 & 99.7 & 3.2 \\
\hline 17 & -1 & 0 & -1 & 0 & 0.16 & 94.8 & 4.3 \\
\hline 18 & 1 & -1 & 0 & 0 & 0.41 & 98.3 & 8.7 \\
\hline 19 & 1 & 0 & -1 & 0 & 0.35 & 95.4 & 5.6 \\
\hline 20 & 0 & 0 & 0 & 0 & 0.52 & 96.6 & 4.4 \\
\hline 21 & 0 & -1 & 1 & 0 & 0.43 & 98.9 & 7.8 \\
\hline 22 & 0 & 1 & 1 & 0 & 0.89 & 99.4 & 6.1 \\
\hline 23 & 1 & 1 & 0 & 0 & 0.87 & 96.6 & 7 \\
\hline 24 & -1 & -1 & 0 & 0 & 0.2 & 95.9 & 7.2 \\
\hline 25 & -1 & 0 & 0 & 1 & 0.35 & 96.2 & 5.4 \\
\hline 26 & 0 & 0 & 0 & 0 & 0.58 & 97.5 & 5.2 \\
\hline 27 & 0 & -1 & 0 & 1 & 0.29 & 98.8 & 2.9 \\
\hline 28 & 0 & 1 & -1 & 0 & 0.38 & 97.3 & 0.9 \\
\hline 29 & -1 & 0 & 1 & 0 & 0.68 & 98.5 & 6.5 \\
\hline
\end{tabular}

\section{RESULTS AND DISCUSSION}

\section{Potato conveying speed}

\section{Regression model establishment and significance test of potato conveying speed}

According to the test scheme and test results in Table 2, multiple regression fitting is carried out, using the data analysis software Design-Expert.13. The regression model of the potato conveying speed is shown in [eq. (4)]. The significance test of the equation is shown in Table 3.

$v=0.526+0.15 \mathrm{~A}+0.1442 \mathrm{~B}+0.1683 \mathrm{C}-0.0492 \mathrm{D}+0.075 \mathrm{AB}+0.0635 \mathrm{AC}-0.0225 \mathrm{AD}-0.065 \mathrm{BC}-0.0125 \mathrm{BD}-0.0075 \mathrm{CD}-0.0388 \mathrm{~A}^{2}-0.0376 \mathrm{~B}^{2}-0.0313 \mathrm{C}^{2}-0.0176 \mathrm{D}^{2}$

Where:

A is the crank rotational speed;

$\mathrm{B}$ is the sieve inclination;
$\mathrm{C}$ is the crank radius,

$\mathrm{D}$ is the swing direction angle. 
TABLE 3. Variance analysis of the regression equation for potato conveying speed.

\begin{tabular}{cccccc}
\hline Source & Sum of squares & Degrees of freedom & F-value & P-value & Significance \\
\hline Model & 0.9649 & 14 & 29.04 & $<0.0001$ & significant \\
A & 0.27 & 1 & 113.76 & $<0.0001$ & significant \\
B & 0.2494 & 1 & 105.08 & $<0.0001$ & significant \\
C & 0.34 & 1 & 143.27 & $<0.0001$ & significant \\
D & 0.029 & 1 & 12.22 & 0.0036 & significant \\
AB & 0.0225 & 1 & 9.48 & 0.0082 & significant \\
AC & 0.0156 & 1 & 6.58 & 0.0224 & significant \\
AD & 0.002 & 1 & 0.8532 & 0.3713 & significant \\
BC & 0.0169 & 1 & 7.12 & 0.0184 & \\
BD & 0.0006 & 1 & 0.2633 & 0.6158 & \\
CD & 0.0002 & 1 & 0.0948 & 0.7627 & \\
$\mathrm{~A}^{2}$ & 0.0098 & 1 & 4.12 & 0.0618 & \\
$\mathrm{~B}^{2}$ & 0.0092 & 1 & 3.86 & 0.0696 & \\
$\mathrm{C}^{2}$ & 0.0064 & 1 & 2.68 & 0.1237 & \\
$\mathrm{D}^{2}$ & 0.002 & 1 & 0.845 & 0.3736 & \\
\hline Residual & 0.0332 & 14 & & & \\
Lack of fit & 0.0287 & 10 & 2.54 & 0.1912 & \\
Pure error & 0.0045 & 4 & & & \\
Total & 0.9981 & 28 & & & \\
\hline
\end{tabular}

Note: $\mathrm{P}<0.01$ (extremely significant); $\mathrm{P}<0.05$ (significant).

Table 3 shows that the regression model of the potato conveying speed has $P<0.01$, indicating that the model is extremely significant. The mismatch criterion $P>$ 0.05 produces no mismatch factors, indicating that the regression model can be used to replace the real point of the test, in order to analyze the results. The model determination coefficient $R^{2}=0.9667$ indicates that the model can reflect a change of $96.67 \%$ in the response value and that the regression model fits the sample points well. In this model, the $P$ values of terms A, B, C, D, and $\mathrm{AB}$ are all less than 0.01 , indicating that the confidence interval of the regression term is within $99 \%$, while the impact on the potato conveying speed is extremely

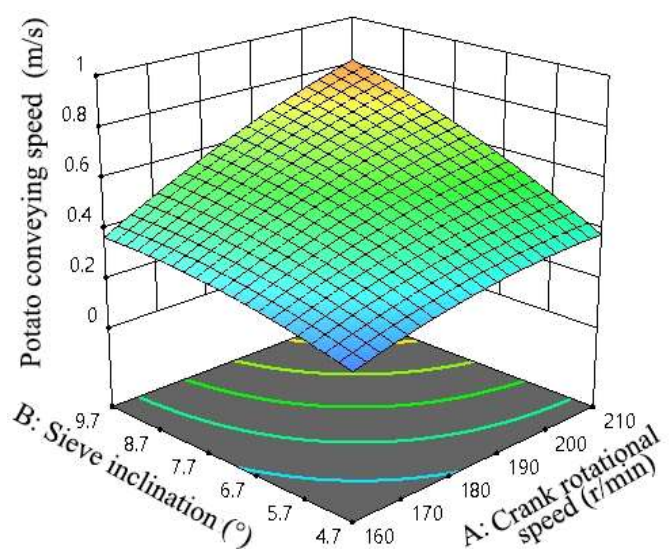

a. $\mathrm{v}=\mathrm{f}(\mathrm{A}, \mathrm{B}, 0,0)$

significant. The $\mathrm{AC}$ and $\mathrm{BC}$ terms are $0.01<P<0.05$, which means that, within the $95 \%$ confidence interval, the impact on the regression model is significant. The $P$ values of the other items are greater than 0.05 , meaning that the impact on the potato conveying speed regression model is not significant.

\section{Response effect analysis of interactive factors on potato conveying speed}

This section only analyzes the response effect between significant items and the potato conveying speed, while non-significant terms are ignored. The response surface analysis is shown in Figure 3.

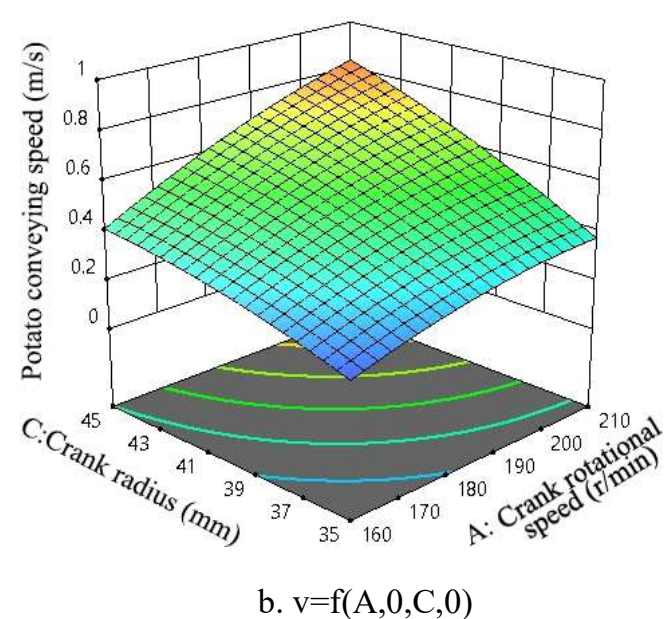




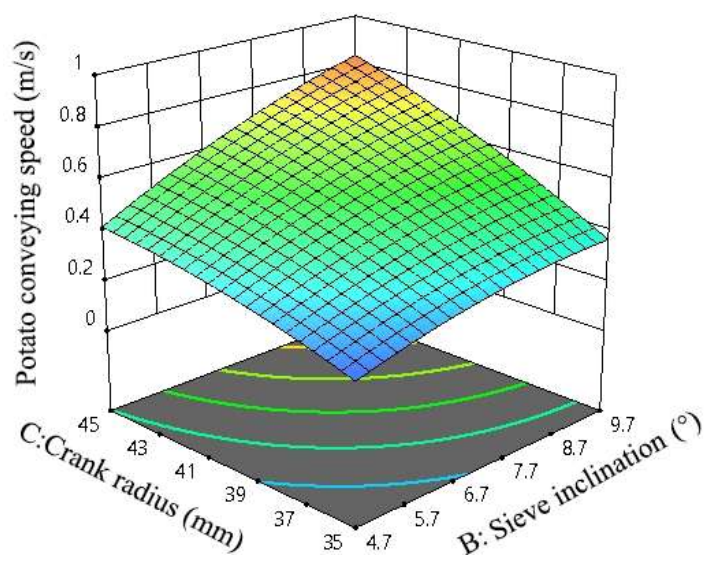

c. $v=f(0, B, C, 0)$

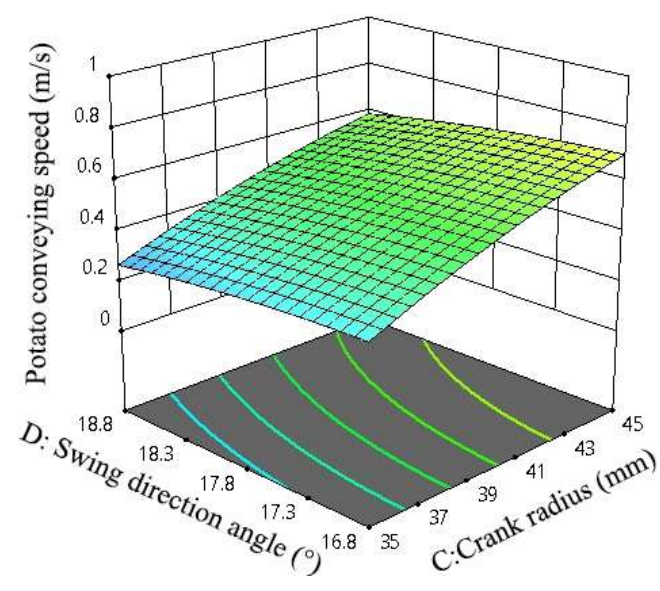

d. $v=f(0,0, C, D)$

FIGURE 3. The influence of interaction factors on the potato conveying speed.

The response surface is defined in the space rectangular coordinates system, which is reflected by the numerical value and is color coded. The color code is defined from low to high as blue $\rightarrow$ green $\rightarrow$ yellow $\rightarrow$ red. Figure 3 shows that the potato conveying speed still exhibits a rising tendency under the interaction of the crank rotational speed, sieve inclination and crank radius with different factors. As the swing direction angle increases, the potato conveying speed shows a decreasing trend. The crank rotational speed affects the swing frequency of the screen body, whose increase accelerates the conveying speed of potatoes. As the inclination angle of the sieve surface increases, the tangential force parallel to the sieve surface rises, thus increasing the downward sliding force of the potatoes along the sieve surface. Higher values of the crank radius increase the swing amplitude of the sieve and the forward sliding displacement of potatoes on the sieve surface. As the swing direction angle grows, the longitudinal force perpendicular to the sieve surface increases and the tangential force parallel to the sieve surface decreases, which also reduces the potato conveying speed.

The interaction terms among the crank rotational speed, sieve inclination and crank radius enhance the potato conveying speed, while the interaction terms are significant in the regression model, as shown in Figure 3. When two factors in the interaction pair increase at the same time, the potato conveying speed increases rapidly. When both factors reach their maximum value, the potato transportation efficiency is the highest.

\section{Potato unearthing rate}

\section{Establishment of regression model and significance test of potato unearthing rate}

The analysis of variance of the potato unearthing rate is carried out and the results are listed in Table 4. The regression equation of the potato unearthing rate is: 
TABLE 4. Variance analysis of the regression equation for potato unearthing rate.

\begin{tabular}{cccccc}
\hline Source & Sum of squares & Degrees of freedom & F-value & P-value & Significance \\
\hline Model & 54.87 & 14 & 9.23 & $<0.0001$ & significant \\
$\mathrm{A}$ & 14.52 & 1 & 34.20 & $<0.0001$ & significant \\
$\mathrm{B}$ & 1.92 & 1 & 4.52 & 0.0517 & \\
$\mathrm{C}$ & 24.08 & 1 & 56.73 & $<0.0001$ & significant \\
$\mathrm{D}$ & 4.81 & 1 & 11.34 & 0.0046 & significant \\
$\mathrm{AB}$ & 0.0625 & 1 & 0.1472 & 0.7070 & \\
$\mathrm{AC}$ & 2.72 & 1 & 6.41 & 0.0239 & significant \\
$\mathrm{AD}$ & 0.0100 & 1 & 0.0236 & 0.8802 & \\
$\mathrm{BC}$ & 0.0225 & 1 & 0.0530 & 0.8213 & \\
$\mathrm{BD}$ & 0.0100 & 1 & 0.0236 & 0.8802 & \\
$\mathrm{CD}$ & 0.0100 & 1 & 0.0236 & 0.8802 & \\
$\mathrm{~A}^{2}$ & 3.17 & 1 & 7.47 & 0.0162 & significant \\
$\mathrm{B}^{2}$ & 0.5870 & 1 & 1.38 & 0.2592 & \\
$\mathrm{C}^{2}$ & 1.47 & 1 & 3.46 & 0.0840 & \\
$\mathrm{D}^{2}$ & 0.2616 & 1 & 0.6162 & 0.4455 & \\
\hline Residual & 5.94 & 14 & & & \\
Lack of fit & 5.01 & 10 & 2.15 & 0.1912 & not significant \\
Pure error & 0.9320 & 4 & & & \\
Total & 60.81 & 28 & & & \\
\hline
\end{tabular}

As can be seen in Table 4, the potato unearthing rate model $P<0.01$, indicating that the established potato unearthing rate regression model is significant, the determination coefficient $R^{2}=0.9023$, while it is concluded that the obtained linear regression equation has a good fitting effect. In the regression model, terms A, C, and $\mathrm{D}$ have extremely significant effects on the potato unearthing rate, $\mathrm{AC}$ and $\mathrm{A}^{2}$ have significant effects on the model, while the other items have no significant impact on the established potato unearthing rate regression model.

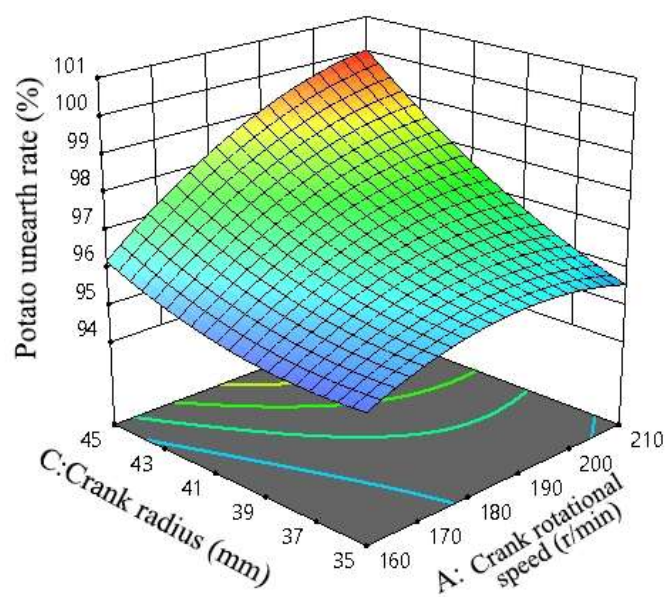

a. $Q=f(\mathrm{~A}, 0, \mathrm{C}, 0)$

\section{Response effect analysis of interactive factors on potato unearthing rate}

The crank rotational speed, crank radius and swing direction angle have a significant effect on the rate of potato unearthing, whereas the interaction mechanism of the crank rotational speed and radius has a significant effect on the rate of potato unearthing. The response effect analysis focuses on the significant items, producing the response surface as shown in Figure 4.

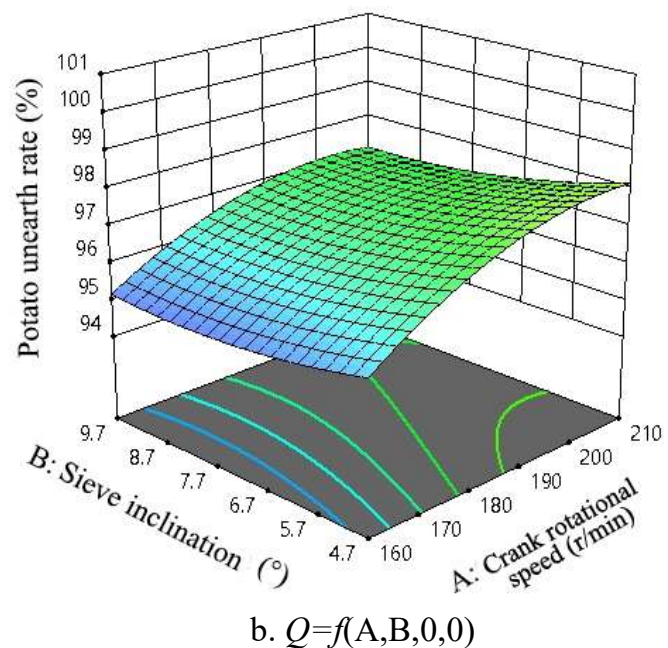




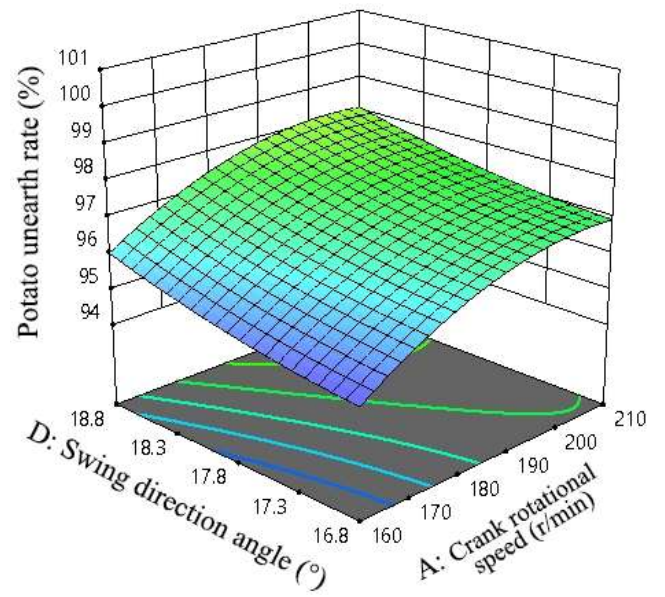

c. $Q=f(\mathrm{~A}, 0,0, \mathrm{D})$

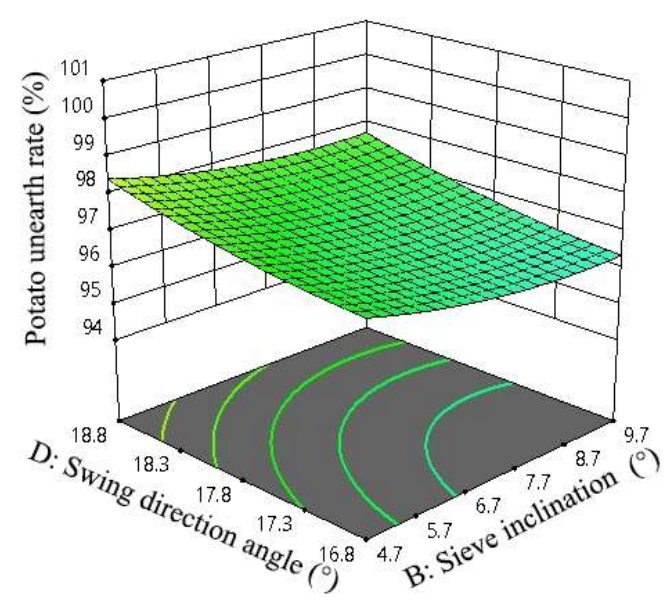

e. $Q=f(0, \mathrm{~B}, 0, \mathrm{D})$

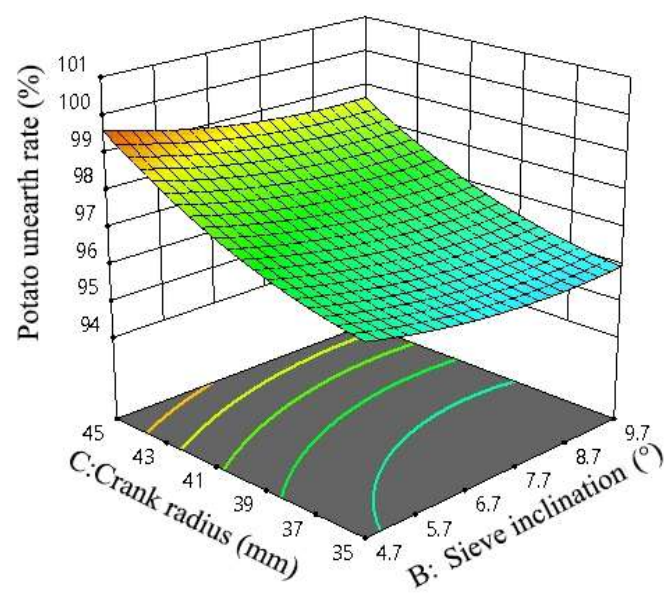

d. $Q=f(0, \mathrm{~B}, \mathrm{C}, 0)$

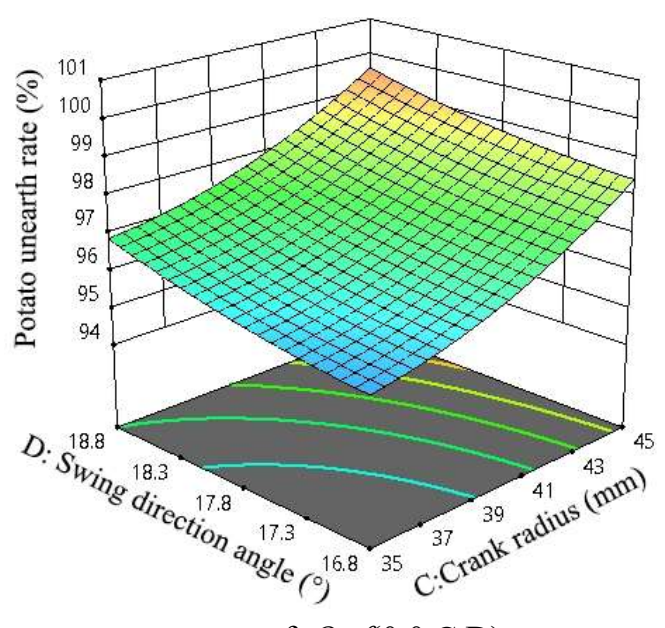

f. $Q=f(0,0, \mathrm{C}, \mathrm{D})$

FIGURE 4. The influence of interaction factors on the potato unearthing rate.

Figure 4a shows that, when the crank radius is 35 37 $\mathrm{mm}$, the influence of the crank rotational speed on the potato unearthing rate first increases and then decreases slowly. Accordingly, when the crank radius is $37 \sim 39 \mathrm{~mm}$, the potato unearthing rate increases, along with the crank rotational speed increase, and tends gradually to a constant value. In the crank radius value range of $35 \sim 45 \mathrm{~mm}$, the potato unearthing rate increases, along with the crank rotational speed. Furthermore, the interaction between the crank radius and rotating speed is significant; that is, when both increase at the same time, the potato unearthing rate increases rapidly; when both reach their maximum value (crank radius $45 \mathrm{~mm}$, rotating speed $210 \mathrm{r} / \mathrm{min}$ ), the potato unearthing rate reaches $100 \%$. Figure $4 \mathrm{~b}$ and $\mathrm{c}$ show that, when the crank rotational speed interacts with the sieve inclination and swing direction angle respectively, the influence trend on the potato unearthing rate is increasing. The increase of the crank rotational speed shortens the motion cycle of the sieve body and decreases the action time span of the potato-soil mixture and sieve surface per unit time, which is conducive to the separation of the potatoes and soil.

Regarding the interaction of the crank radius with other factors, Figures $4 \mathrm{a}$, $\mathrm{d}$ and $\mathrm{f}$ show that, as the crank radius increases, the potato unearthing rate response curve slope is greater than 1 and the potato unearthing rate rises rapidly. Furthermore, the swing amplitude of the sieve body, as well as the acceleration of the potato-soil mixture in the $\mathrm{X}$ and $\mathrm{Y}$ directions, also increases. If the crank radius continues to increase, the motion state of the potatosoil mixture in the swing screen changes from reciprocating sliding to slight jumping and then progresses to violent jumping. The proper increase of the crank radius is conducive to the dispersion, penetration and shear of soil blocks, while the rate of potato unearthing is also improved.

Considering the interaction of the sieve inclination with other factors, Figures $4 \mathrm{~b}, \mathrm{~d}$ and e show that the influence trend on the potato unearthing rate is gradually becoming lighter, the contribution to the potato unearthing rate is greater than the swing direction angle, while the influence of the sieve inclination on the potato unearthing rate is close to significant. Figures $4 \mathrm{c}$, e and f show that the influence of the swing direction angle on the potato unearthing rate gradually increases.

\section{Potato damage rate}

Establishment of regression model and significance test of potato damage rate

The analysis of variance of the potato damage rate is carried out and the results are listed in Table 5. The regression equation of the potato damage rate is: 
TABLE 5. Variance analysis of the regression equation for potato damage rate.

\begin{tabular}{|c|c|c|c|c|c|}
\hline Source & Sum of squares & Degrees of freedom & F-value & P-value & Significance \\
\hline Model & 162.17 & 14 & 31.30 & $<0.0001$ & significant \\
\hline A & 8.00 & 1 & 21.63 & 0.0004 & significant \\
\hline B & 13.44 & 1 & 36.32 & $<0.0001$ & significant \\
\hline $\mathrm{C}$ & 52.50 & 1 & 141.88 & $<0.0001$ & significant \\
\hline $\mathrm{D}$ & 0.0300 & 1 & 0.0811 & 0.7800 & \\
\hline $\mathrm{AB}$ & 0.3600 & 1 & 0.9729 & 0.3407 & \\
\hline $\mathrm{AC}$ & 0.0025 & 1 & 0.0068 & 0.9357 & \\
\hline $\mathrm{AD}$ & 0.0625 & 1 & 0.1689 & 0.6873 & \\
\hline $\mathrm{BC}$ & 0.0900 & 1 & 0.2432 & 0.6295 & \\
\hline $\mathrm{BD}$ & 0.0025 & 1 & 0.0068 & 0.9357 & \\
\hline $\mathrm{CD}$ & 7.29 & 1 & 19.70 & 0.0006 & significant \\
\hline$A^{2}$ & 39.65 & 1 & 107.16 & $<0.0001$ & significant \\
\hline $\mathrm{B}^{2}$ & 2.66 & 1 & 7.18 & 0.0180 & significant \\
\hline $\mathrm{C}^{2}$ & 0.0006 & 1 & 0.0018 & 0.9672 & \\
\hline $\mathrm{D}^{2}$ & 22.86 & 1 & 61.79 & $<0.0001$ & significant \\
\hline Residual & 5.18 & 14 & & & \\
\hline Lack of fit & 4.59 & 10 & 3.12 & 0.1418 & not significant \\
\hline Pure error & 0.5880 & 4 & & & \\
\hline Total & 167.35 & 28 & & & \\
\hline
\end{tabular}

According to Table 5, if the potato damage rate model $P<0.01$, the regression model is significant, while the determination coefficient $R^{2}=0.969$ shows that the fitting effect of the obtained linear regression equation is good. In this model, items $\mathrm{A}, \mathrm{B}, \mathrm{C}, \mathrm{CD}, \mathrm{A}^{2}, \mathrm{D}^{2}$ have extremely significant effects on the regression model, item $\mathrm{B}^{2}$ has a significant impact on the model, whereas the other items have no significant impact on the regression model of the potato damage rate.

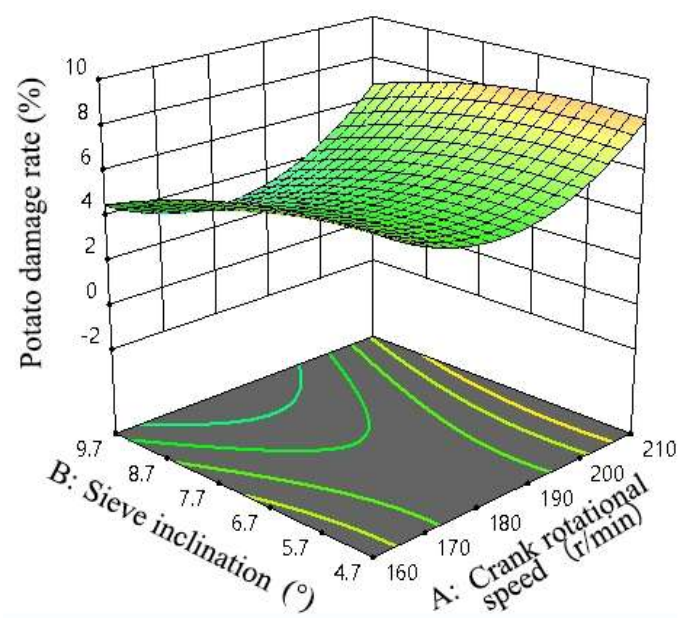

a. $Z=f(\mathrm{~A}, \mathrm{~B}, 0,0)$

\section{Response effect analysis of interactive factors on potato damage rate}

The crank rotational speed, sieve inclination, crank radius, the interaction term between the crank radius and swing direction angle, the quadratic term of the crank rotational speed, as well as the quadratic term of the swing direction angle, all have extremely significant effects on the potato damage rate. The response effect of significant items is analyzed in Figure 5.

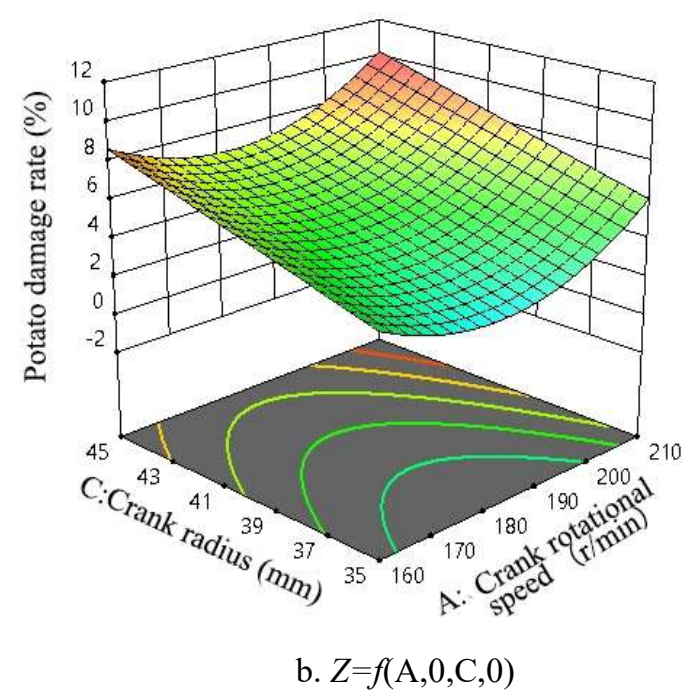




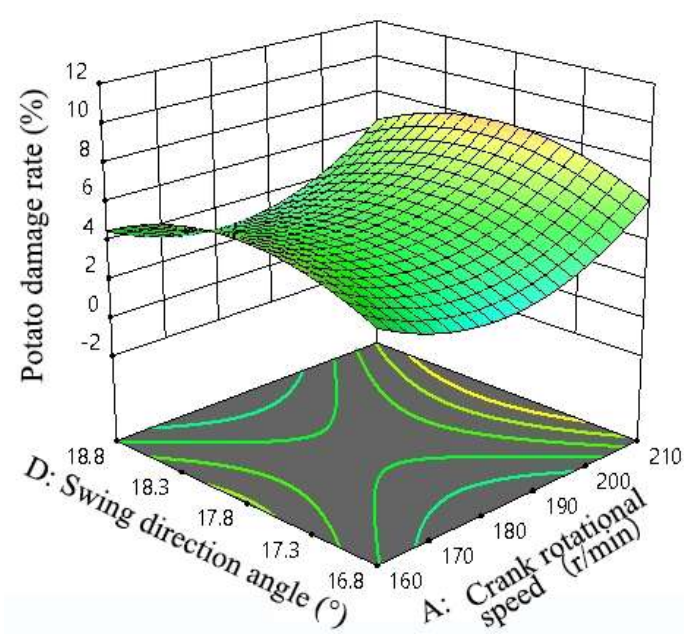

c. $Z=f(\mathrm{~A}, 0,0, \mathrm{D})$

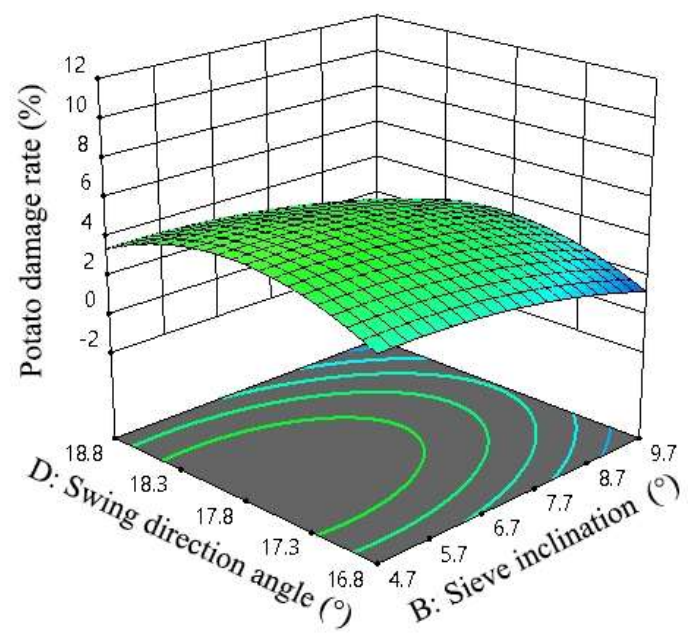

e. $Z=f(0, \mathrm{~B}, 0, \mathrm{D})$

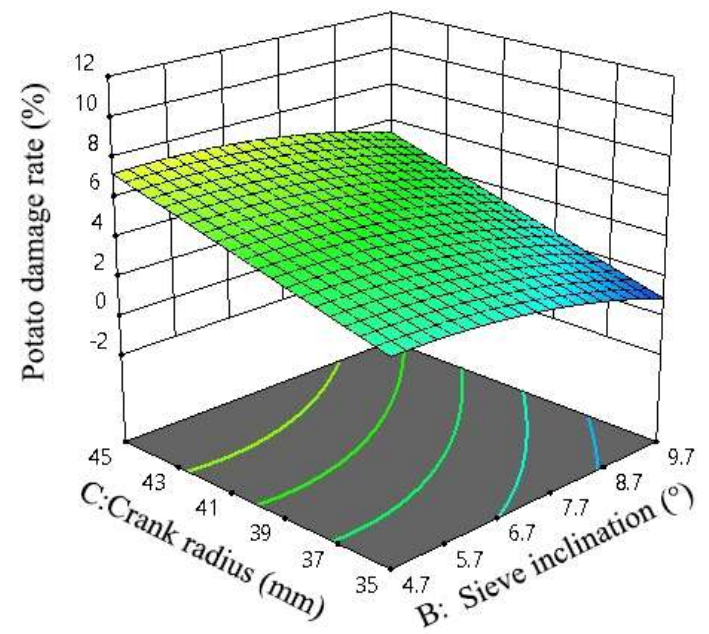

d. $Z=f(0, \mathrm{~B}, \mathrm{C}, 0)$

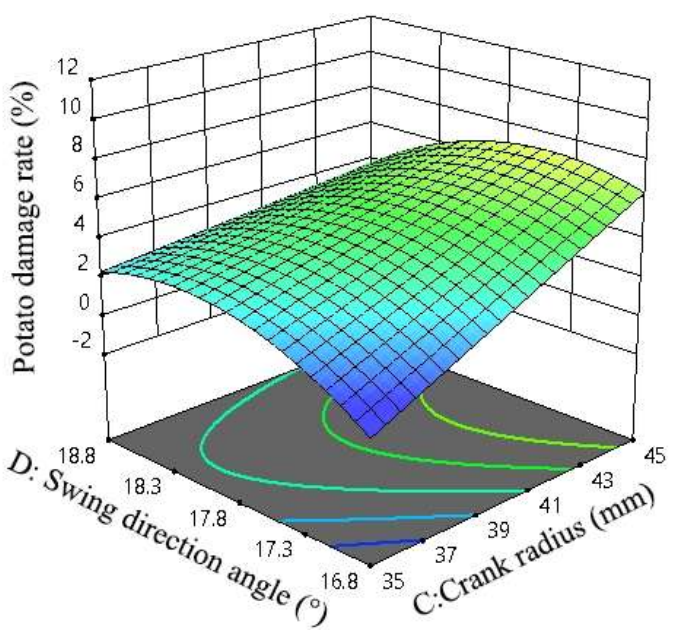

f. $Z=f(0,0, \mathrm{C}, \mathrm{D})$

FIGURE 5. The influence of interaction factors on the potato damage rate.

Figure $5 \mathrm{f}$ shows the response surface, in regard to the crank radius and the swing direction angle of the significant interaction term. The potato damage rate rises along with the increase of the crank radius, while it initially increases and then decreases slowly with the increase of the swing direction angle. The potato damage rate is the lowest when both factors are at their respective minimum values; that is, the crank radius is $35 \mathrm{~mm}$ and the swing direction angle is $16.8^{\circ}$.

In regard to the interaction of the crank rotational speed with other factors, Figures $5 \mathrm{a}, \mathrm{b}$ and $\mathrm{c}$ show that the influence trend on the potato damage rate first appears to gradually drop, followed by a gradual rise. When the crank rotational speed ranges between 180 and $200 \mathrm{r} / \mathrm{min}$, the potato damage is at a minimum value. The increase of the crank rotational speed shortens the action time of the potato-soil mixture and the sieve surface, speeds up the transportation speed of potatoes, reduces the friction time between the potatoes and sieve surface, improves the unearthing of the potatoes and reduces the skin damage to the potatoes. However, excessive rotating speed easily causes the potatoes to jump on the sieve surface, resulting in internal damage and increased potato damage.
According to Figures 5a, d and e, when the sieve inclination interacts with different factors, the influence on the damaged potato rate is gradually reduced. As the inclination angle of the sieve increases, the conveying speed of the potatoes is improved and the skin damage to the potatoes is reduced.

Based on the illustrations in Figures $5 \mathrm{~b}$, d and f, when the crank radius interacts with different factors, the influence on the potato damage rate has an increasing trend. Higher values of the crank radius make the potato move with a large acceleration along the $\mathrm{X}$ and $\mathrm{Y}$ directions of the sieve. At extremely high values of the crank radius, the motion mode of the potatoes on the sieve surface is mainly a jumping motion, especially in the middle and later area of the sieve surface, where the potato collides with the sieve, as it is covered by only a thin (or none) layer of soil, resulting in serious damage to the potato.

\section{Contribution rate of various parameters to the screening indexes}

The contribution rate $\Delta_{j}$ can reflect the degree of influence of a single parameter on the established regression model. A higher $\Delta j$ means a greater degree of influence (Liu et al. 2020). The calculation formula of $\Delta j$ is as follows: 


$$
\begin{aligned}
& \gamma= \begin{cases}0 & F \leq 1 \\
1-\frac{1}{F} & F>1\end{cases} \\
& \Delta_{j}=\gamma_{j}+\frac{1}{2} \sum_{\substack{i=1 \\
i \neq j}}^{m} \gamma_{i j}+\gamma_{j j} \quad j=1,2, \Lambda, m
\end{aligned}
$$

Where:

$F$ is the F-value of the analysis of variance;

$\gamma$ is the appraisal value;

$\Delta_{j}$ is the contribution rate;

$\gamma_{j}$ is the contribution rate of the first term of the $j$-th parameter; $\gamma_{j j}$ is the contribution rate of the quadratic term of the $\mathrm{j}$-th parameter,

$\gamma_{i j}$ is the contribution rate of the interaction between the $\mathrm{j}$-th and other parameters.

The contribution rate of each parameter to the screening indexes is calculated according to eqs (7) and (8), as shown in Table 6. Specifically, the influence on the potato conveying speed ranks as follows: crank rotational speed $>$ sieve inclination $>$ crank radius $>$ swing direction angle; the order of the influence on the potato unearthing rate is: crank rotational speed $>$ crank radius $>$ sieve inclination > swing direction angle; the influence order on the potato damage rate is crank radius $>$ crank rotational speed $>$ sieve inclination $>$ swing direction angle.

TABLE 6. Contribution rate of each parameter to the screening indexes.

\begin{tabular}{cccc}
\hline Parameters & $\begin{array}{c}\text { Contribution rate } \\
\text { (potato conveying speed) }\end{array}$ & $\begin{array}{c}\text { Contribution rate (potato } \\
\text { unearthing rate) }\end{array}$ & $\begin{array}{c}\text { Contribution rate } \\
\text { (potato damage rate) }\end{array}$ \\
\hline $\mathrm{A}$ & 2.24112 & 1.82582 & 1.44911 \\
$\mathrm{~B}$ & 2.23798 & 0.91644 & 1.40283 \\
$\mathrm{C}$ & 2.16024 & 1.75986 & 1.46757 \\
$\mathrm{D}$ & 0.91817 & 0.91181 & 0.96656 \\
\hline
\end{tabular}

\section{Screening parameter optimization and test verification}

\section{Optimization of screening parameters}

In order to improve the screening performance of the swing separation sieve, on the premise of a good potato-soil separation effect, the highest possible potato transport efficiency is an essential requirement. Therefore, the optimization objectives of the highest potato unearthing rate, lowest damaged potato rate and highest potato conveying speed provide the objective functions and constraints of the parameter variables, as shown in [eq. (9)]. The optimal solution module of Design-Expert is used to solve the regression model. The optimal working parameters of the swing separation sieve are derived as: crank speed of $193.378 \mathrm{r} / \mathrm{min}$, screen inclination of $9.7^{\circ}$, crank radius of $45 \mathrm{~mm}$ and swing direction angle of $18.8^{\circ}$. With these, the rate of potato unearthing is $100 \%$, the rate of damaged potatoes is $2.966 \%$ and the potato conveying speed is $0.832 \mathrm{~m} / \mathrm{s}$.

$$
\left\{\begin{array}{l}
\max v \\
\max Q \\
\min Z \\
160 \mathrm{r} / \mathrm{min} \leq \mathrm{A} \leq 210 \mathrm{r} / \mathrm{min} \\
4.7^{\circ} \leq \mathrm{B} \leq 9.7^{\circ} \\
35 \mathrm{~mm} \leq \mathrm{C} \leq 45 \mathrm{~mm} \\
16.8^{\circ} \leq \mathrm{B} \leq 18.8^{\circ}
\end{array}\right.
$$

According to the optimization results, the appropriate crank rotational speed matches the largest crank radius, sieve inclination and swing direction angle, which not only improve the potato-soil separation effect and transportation efficiency, but also reduce the potato damage. The main reason is that, when all the parameters assume large values, the potato-soil separation performance and the material transportation performance of the swing sieve are both high. At the same time, increasing the feeding volume of the potato-soil mixture (or increasing the excavation depth and increasing the soil proportion in the mixture) enhances the protective effect of soil on the potatoes, so they fall to the ground after jumping $1 \sim 2$ times on the sieve surface, reducing the induced damage and improving the harvesting efficiency of the excavator.

\section{Test verification}

In order to verify the reliability of the optimization model of the swing separation sieve, field experiments were carried out in a test area, according to the above optimal screening parameter combination. During the pretesting of the potato digger, due to the uneven ground and irregular shape of the potatoes, a small number of potatoes will move laterally (perpendicular to the potato block conveying direction) on the sieve surface and will thus be more prone to skin damage. This is mainly due to the excessive swing amplitude of the sieve. The length of the crank should be appropriately reduced in order to reduce the lateral sliding displacement of the potatoes. Considering the feasibility and operability of the test, the optimal working parameters are adjusted as follows: crank 
rotational speed $190 \mathrm{r} / \mathrm{min}$, sieve inclination $9.7^{\circ}$, crank radius $40 \mathrm{~mm}$ and swing direction angle $18.8^{\circ}$. The test is repeated 5 times and the average value of each metric is considered as the test results. The average values of the potato conveying speed, potato unearthing rate and damaged potato rate are $0.713 \mathrm{~m} / \mathrm{s}, 98.7 \%$ and $3.224 \%$, respectively. The relative deviation between each evaluation index and the respective theoretical optimized value are listed in Table 7.

TABLE 7. Measured value of evaluation indices under optimal condition.

\begin{tabular}{cccc}
\hline Item & Conveying speed $(\mathrm{m} / \mathrm{s})$ & Unearthing rate $(\%)$ & Damage rate $(\%)$ \\
\hline Test average & 0.713 & 98.7 & 3.224 \\
Optimal value & 0.832 & 100 & 2.966 \\
Relative error $(\%)$ & 11.9 & 1.3 & 8.6 \\
\hline
\end{tabular}

The set of swing separation sieve parameters, before optimization, is crank rotational speed $160 \mathrm{r} / \mathrm{min}$, sieve inclination $7.6^{\circ}$, crank radius $35 \mathrm{~mm}$ and swing direction angle $16.8^{\circ}$. Comparison of the optimized test results to the previous ones is listed in Table 8 .

TABLE 8. Comparison of test results before and after optimization.

\begin{tabular}{cccc}
\hline Item & Conveying speed $(\mathrm{m} / \mathrm{s})$ & Unearthing rate $(\%)$ & Damage rate $(\%)$ \\
\hline After optimization & 0.713 & 98.7 & 3.224 \\
Before optimization & 0.294 & 96.3 & 8.157 \\
National standard & & $>96$ & $<5$ \\
\hline
\end{tabular}

Table 7 shows that the test results are consistent with the theoretical optimization values, the relative error is small and the parameter model is reliable. After the optimization of the screening index, compared to the non-optimized operation, the potato conveying speed increased by 1.43 times, the potato unearthing rate increased by $2.5 \%$ and the damaged potato rate decreased by $60 \%$, as shown in Table 8 . After optimization, the screening performance of the swing separation sieve appears to be greatly improved and is according to the technical specifications of potato harvest evaluation.

\section{CONCLUSIONS}

(1) The influence mechanism of a swing separation sieve on the sieving characteristics of potato-soil mixture was obtained through comprehensive experimental analysis. There is a linear relationship between the screening parameters and screening indexes, indicating the following influence: the potato conveying speed increases with the increase of the crank rotational speed, sieve inclination, crank radius and the decrease of the swing direction angle. The potato unearthing rate increases with the increase of the crank radius, swing direction angle and the decrease of the sieve inclination. When the crank rotational speed interacts with different parameters, the influence on the potato unearthing rate shows different trends. The rate of potato damage first decreased and then increased as the crank rotational speed increased. The rate of potato damage decreased as the sieve inclination increased and the crank radius decreased. The rate of potato damage first decreased and then increased as the swing direction angle increased.
(2) The optimum combination of parameters for the swing separation sieve is: crank rotational speed $190 \mathrm{r} / \mathrm{min}$, sieve inclination $9.7^{\circ}$, crank radius $40 \mathrm{~mm}$ and swing direction angle $18.8^{\circ}$. The corresponding optimized potato conveying speed, potato unearthing rate and damaged potato rate are $0.713 \mathrm{~m} / \mathrm{s}, 98.7 \%$ and $3.224 \%$, respectively. After optimization, the potato conveying speed increased by 1.43 times, the potato unearthing rate increased by $2.5 \%$, while the damaged potato rate decreased by $60 \%$. The screening performance of the swing separation sieve has been greatly improved and the work is stable.

\section{ACKNOWLEDGMENTS}

This work was supported by the National Natural Science Foundation of China (Grant No. 31901409), Natural Science Foundation of Inner Mongolia Autonomous Region (Grant No. 2018LH05015), and Innovation Fundation of Inner Mongolia University of Science and Technology (Grant No. 2017QDL-B09), and Educational Reform Research and Practice Project of Henan Institute of Technology (Grant No. 2021-YB023), and Key Research Development and Promotion Special Project of Henan Province (Grant No. 212102310119 and 212102210358).

\section{REFERENCES}

Cui YJ, Wang WQ, Wang MH, Ma YD, Fu LS (2021) Effects of cutter parameters on shearing stress for lettuce harvesting using a specially developed fixture. International Journal of Agricultural and Biological Engineering 14(4):152-158. DOI: 10.25165/j.ijabe.20211404.6346 
Fu QK, Fu J, Chen Z, Cheng C, Ren LQ (2018)

Optimization of working parameters on soil removal of stover pickup baler by vibration. Transactions of the Chinese Society of Agricultural Engineering 34(08):26-33. DOI: $10.11975 /$ j.issn.1002-6819.2018.08.004

Liu P, Jin CQ, Liu Z, Zhang GY, Cai ZY, Kang Y, Yin X (2020) Optimization of field cleaning parameters of soybean combine harvester. Transactions of the Chinese Society of Agricultural Engineering 36(10):35-45. DOI: 10.11975/j.issn.1002-6819.2020.10.005

Lv JQ, Tian ZN, Wu JE, Yang Y, Shang QQ, Wang YB, Liu ZX (2015) Design and experiment on 4 U1Z vibrating potato digger. Transactions of the Chinese Society of Agricultural Engineering 31(12):39-47. DOI:

10.11975/j.issn.1002-6819.2015.12.006

Meng JG, Li YH, Wang CG, Wang B, Yv QH, Xie WX (2020) Kinetic Characteristic Research of Potato on the Swing Screen Based on Discrete Element Method. Journal of Agricultural Mechanization Research 42(01):19-24.

DOI: CNKI:SUN:NJYJ.0.2020-01-005

Meng JG, Zhao X, Wang K, Ren QK, Lv LG, Xie SS, Wang CG (2022) Research Status of Potato Harvesters in China in the Past Decade_ — Based on the Knowledge Map Analysis of Cite space. Journal of Agricultural Mechanization Research 44(02):1-8. DOI:

10.13427/j.cnki.njyi.2022.02.001

Shi LR, Wu JM, Zhao WY, Sun W, Wang D, Li H, Liu QW (2012) Design and experiment on potato digger of disc ce-grate type. Transactions of the Chinese Society of Agricultural Engineering 28(24):15-21. DOI:

10.3969/j.issn.1002-6819.2012.24.003

Wang B, Hu ZC, Peng BL, Zhang YH, Gu FW,Shi LL, Gao XM (2017a) Structure operation parameter optimization for elastic steel pole oscillating screen of semi-feeding four rows peanut combine harvester.

Transactions of the Chinese Society of Agricultural Engineering 33(21):20-28. DOI:

10.11975/j.issn.1002-6819.2017.21.002

Wang XY, Sang JB, Xv YC, Li XQ, Cheng PF (2017b) Design and Experiment of Potato Cleaning and Sorting Machine. Transactions of the Chinese Society for Agricultural Machinery 48(10):316-322+279. DOI: 10.6041/j.issn.1000-1298.2017.10.040
Wei ZC, Li HW, Sun CZ, Li XQ, Liu WZ, Su GL,Wang FM (2018) Improvement of potato harvester with two segment of vibration and wave separation. Transactions of the Chinese Society for Agricultural Engineering 34(12):42-52. DOI: 10.11975/j.issn.1002-6819.2018.12.006

Wu JM, Li H, Sun W, Huang XP, Sun BG (2010) Design of Potato Digger in Poke Finger's Wheel Type.

Transactions of the Chinese Society for Agricultural Machinery 41(12):76-79. DOI:

10.3969/j.issn.1000-1298.2010.12.016

Wu JM, Li H, Sun W, Huang XP, Zhang W (2011)

Experiment on poke finger wheel type potato digger. Transactions of the Chinese Society for Agricultural Engineering 27(07):173-177. DOI: 10.3969/j.issn.1002-6819.2011.07.030

Xin LL, Liang JH, Wen BC (2009) Dynamic Analysis of a Vibrating Conveyer with Inclination in Consideration of Material Combination Coefficient. Transactions of the Chinese Society for Agricultural Machinery 40(02):87-90. DOI: CNKI:SUN:NYJX.0.2009-02-019

Xie SS, Wang CG, Deng WG (2019) Experiment of a swing separating sieve on a potato digger. Engenharia Agrícola 39(4):548-554.

DOI:10.1590/1809-4430-eng.agric.v39n4p548-554/2019

Xie SS, Wang CG, Deng WG, Li X, Qi SH (2017)

Separating Mechanism Analysis and Parameter Optimization Experiment of Swing Separation Sieve for Potato and Soil Mixture. Transactions of the Chinese Society for Agricultural Machinery 48(11):156-164. DOI: 10.6041/j.issn.1000-1298.2017.11.019

Yang RB, Yang HG, Shang SQ, Xv PX, Cui GP, Liu LH (2016) Design and Test of Poking Roller Shoving Type Potato Harvester. Transactions of the Chinese Society for Agricultural Machinery 47(07):119-126. DOI:

10.6041/j.issn.1000-1298.2016.07.017

Zhang ZG, Wang HY, Li YB, Yang X, IBRAHIM Issa, Zhang ZD (2021) Design and Experiment of Multi-stage Separation Buffer Potato Harvester. Transactions of the Chinese Society for Agricultural Machinery 52(02):96-109. DOI: $10.6041 / \mathrm{j}$.issn. 1000-1298.2021.02.009 